\title{
Interactive Web-based Hydrological Simulation System as an Education Platform using Augmented and Immersive Reality
}

\author{
Ibrahim Demir
}

Iowa Flood Center, IIHR Hydroscience \& Engineering, Civil and Environmental Engineering

Department, University of Iowa, Iowa City, IA, USA

\begin{abstract}
Recent developments in internet technologies make it possible to manage and visualize large data on the web. Novel visualization techniques and interactive user interfaces allow users to create realistic environments, and interact with data to gain insight from simulations and environmental observations. The hydrological simulation system is a webbased 3D interactive learning environment for teaching hydrological processes and concepts. The simulation system provides a visually striking platform with realistic terrain information, and water simulation. Students can create or load predefined scenarios, control environmental parameters, and evaluate environmental mitigation alternatives. The web-based simulation system provides an environment for students to learn about the hydrological processes (e.g. flooding and flood damage), and effects of development and human activity in the floodplain. The system utilizes latest web technologies and graphics processing unit (GPU) for water simulation and object collisions on the terrain. Users can access the system in three visualization modes including virtual reality, augmented reality, and immersive reality using heads-up displays. The system provides various scenarios customized to fit the age and education level of various users. This paper provides an overview and capabilities of the webbased hydrological simulation system for simulating various flooding and land use scenarios.
\end{abstract}

\section{Introduction}

A significant amount of hydrological and meteorological data is collected every day by a wide range of sensors and instruments that range from in-stream sensors to ground- and space-based remote sensing platforms. Daily environmental data collection was over 25 terabytes in $2009^{1}$. Information contained in the available data cannot be fully utilized if they are not easily accessible and properly structured. Environmental Information Systems (EIS) are gaining importance for addressing grand scientific challenges in environmental monitoring and prediction ${ }^{2,3}$ by providing integrated multi-disciplinary platforms that combine data management, visualization, analysis, modeling, and information communication capabilities ${ }^{4}$.

Information systems play an important role in many geoscience disciplines, including hydrology and atmospheric science ${ }^{5,6,7}$. Recent examples of these systems have capabilities for web-based management, visualization, and shared environmental time-series data using web services ${ }^{8,9}$. A critical application domain for these systems with real-time information and visualization is interactive learning platforms. Recent developments in information and Internet technologies provide a great opportunity to enhance the understanding of 
hydrological concepts and processes using web-based visualization with novel interaction and communication capabilities.

The project aims at developing a web-based interactive simulation environment to introduce hydrological concepts in engineering and science curriculum. This project builds upon the preliminary work done with the support and funding at Google Summer of Code 2013 program. The project integrates latest web technologies and novel communication and interaction hardware (e.g. Oculus Rift, Leap Motion and Microsoft Kinect controllers) for teaching hydrological concepts in a game-style fun and engaging educational simulation environment. The platform have three visualization modes to support virtual, augmented and immersive reality technologies. The simulation environment is designed to be integrated to the introductory and advanced environmental science curriculum, and provide an interactive learning environment and hands-on experience in hydrological concepts for students from various engineering and science backgrounds. This paper provides an overview and features of the web-based hydrological simulation system with its novel visualization and interaction capabilities.

\section{Platform Capabilities}

The simulation environment allows introduction of concepts in hydrology and environmental sciences including watershed, precipitation, river network, drainage, flood inundation, reservoirs, levees, etc. Students can load various environmental scenarios, control specific parameters in the scenario settings, and observe the actual effects of the flooding in Iowa communities. The platform allows students to control reservoir water levels, levee locations, and several management actions to mitigate flooding, and test management actions in reallife scenarios, and evaluate performance of mitigation options. The platform creates a realistic animation of the flooding within the watershed and calculate the damage (e.g. area under flood, property, life, direct and indirect costs, etc.). The platform includes scenarios for historical events (e.g. 2008 Iowa Floods), and integrate real-time rainfall data and flood maps from Iowa Flood Information System ${ }^{10}$, and allow students to work with actual data for over 1000 communities in Iowa. The Iowa Flood Information System (IFIS) is a web-based

platform developed by the Iowa Flood Center (IFC) to provide access to flood inundation maps, real-time flood conditions, flood warnings and forecasts, flood-related data, information and interactive visualizations for communities in Iowa. Real-time data of over 500 stream sensors from various sources (e.g., USGS, NWS, USACE, IFC Sensors, etc.) are integrated into the IFIS. A RESTfull (Representational State Transfer) web service is used in the system to access real-time data in IFIS using common data formats (e.g. XML) similar to other web services in different environmental applications ${ }^{11,12}$. 


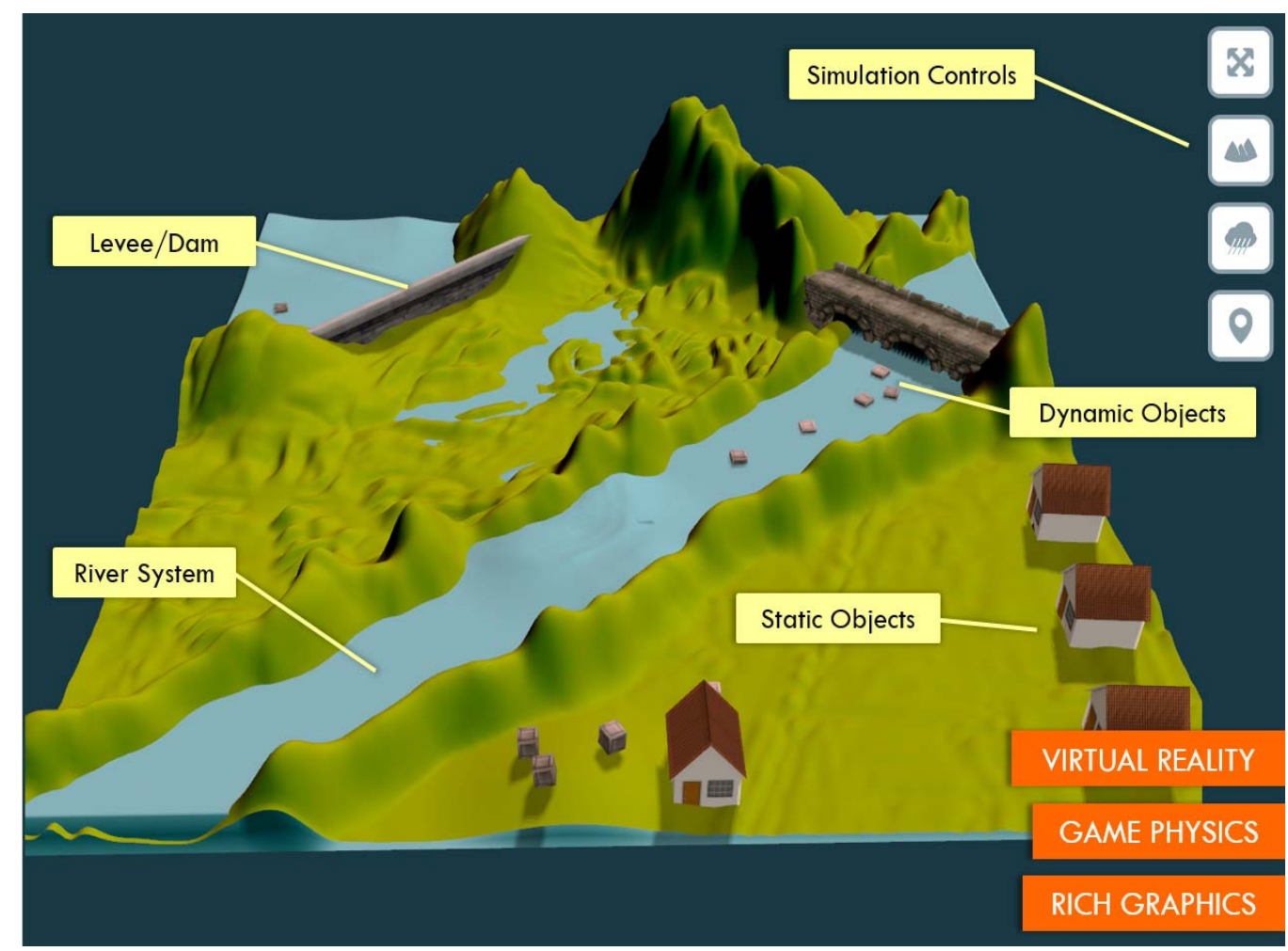

Figure 1. Virtual reality visualization mode of the platform

\section{Visualization Modes}

The simulation platform provides three modes for visualization and interaction including Virtual Reality, Augmented Reality and Immersive Reality. Virtual Reality mode (Figure1) creates 3D visualization of the simulation on a screen where users can interact using a keyboard and mouse. The system also allows remote interaction of the platform using a smartphone or tablet. This enables interaction of the system by multiple users collaboratively working on different part of the simulation during the teaching process.

Augmented Reality mode (Figure 2) requires a camera to locate and track markers on a physical desktop, and overlay the virtual simulation environment on the table. A webcam or smartphone/tablet camera can be used to capture real-time video feed and locate markers. The system supports interacting with multiple markers with various functions like controlling the scene, adding/removing water, modifying terrain, etc.

Immersive reality allows a person to enter a virtual environment and embody it in such a way as to actively inhabit and interact ${ }^{13,14}$. Immersive Reality mode (Figure 3 ) requires a heads-up display to visualize the virtual system around the user. The head tracking feature of the heads-up display allows visualization oriented around the user's point of view and creates an immersive experience. 


\section{Learning Opportunities}

The instructors can load scenarios interactively and demonstrate historical events through a web-browser in a classroom environment. The platform is optimized for use and control with tablets and smartphones on iOS and Android platforms. The concepts are explained with definitions and references to online resources in the platform for further learning and study opportunities. Students are interactively provided hands-on experience in hydrological concepts, management actions, and effects of flooding in actual communities in Iowa.

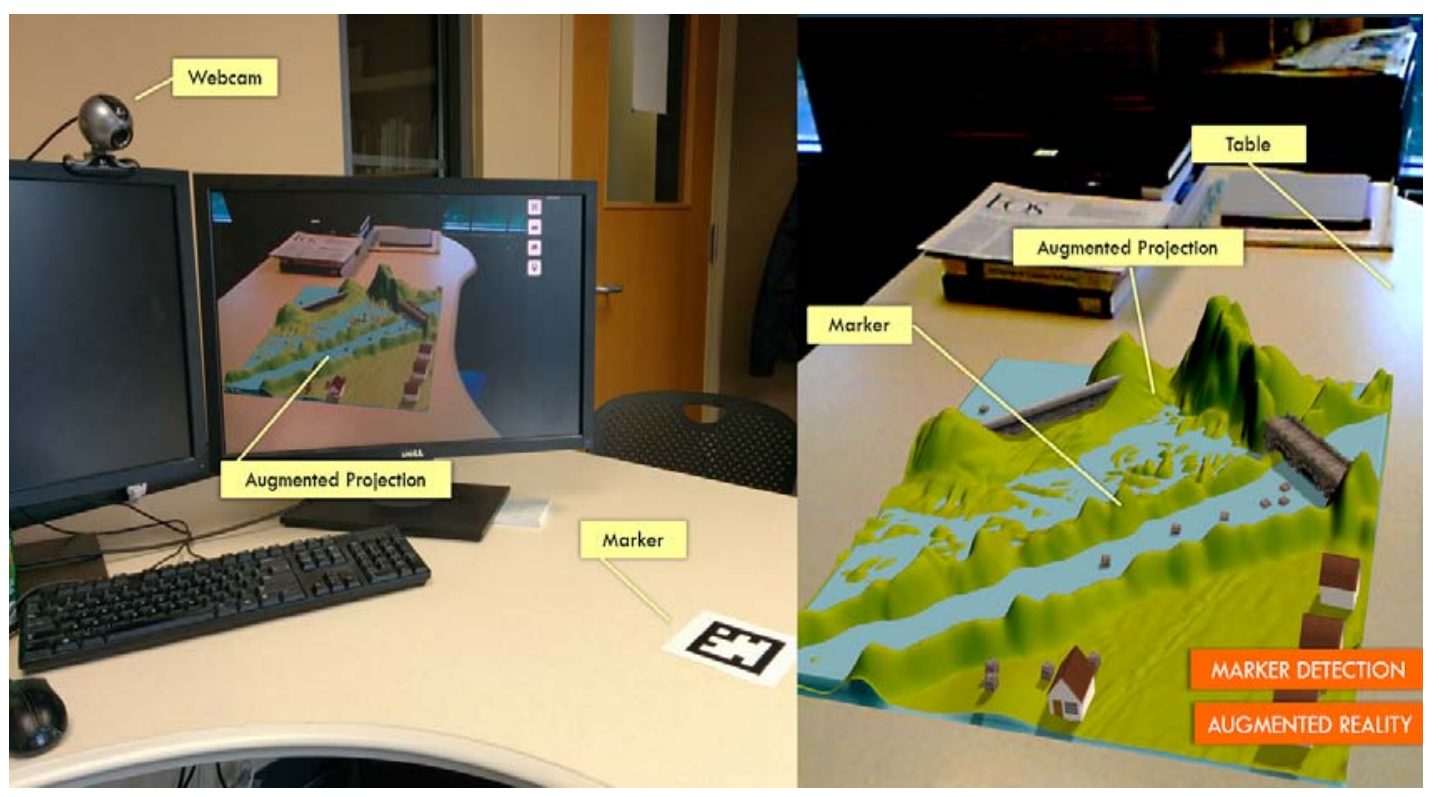

Figure 2. Augmented reality visualization mode of the platform

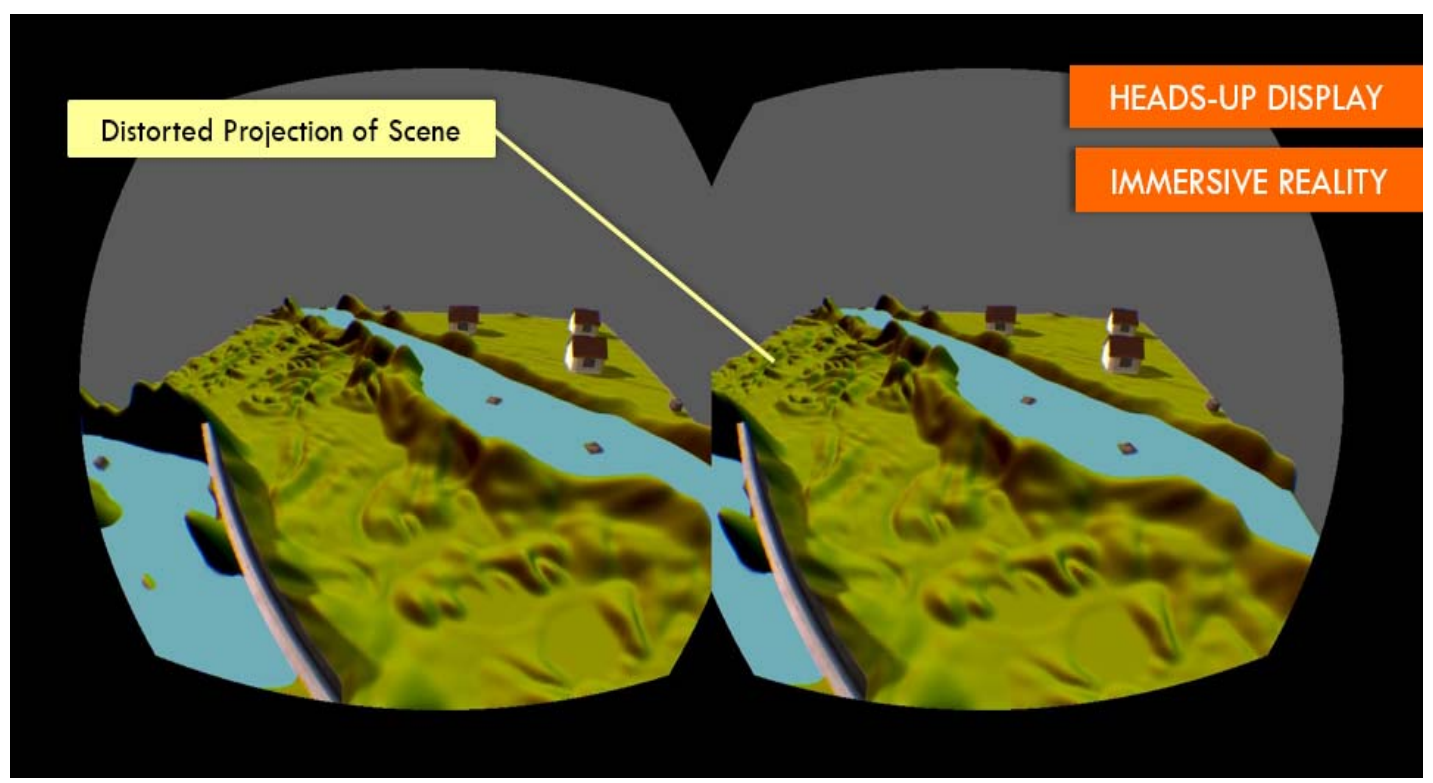

Figure 3. Immersive reality visualization mode for heads-up displays 
The platform raises the student's interest in environmental curriculum. Integration of realtime data resources make it easy for students to work with actual data. Rich visualizations and animations can attract students, and game-style performance evaluations provide a competition environment for better management actions via in-game scores for saving land and reducing damage of floods with proper action. The platform also integrates gesture based technologies to allow students to interact with the platform using their hands and body movement. The proposed project can assist instructors as an interactive simulation environment in supporting their curriculum.

Benefits of the platform in terms of teaching and learning opportunities are listed below:

- New hydrological and environment concepts can be easily integrated into the online learning environment

- Student can get hand-on experience on flooding with actual data and communities in Iowa

- Web-based platform makes it easy for any instructor to integrate the platform to their curriculum using a web-browser

- Students can learn how hydrological systems work and how they are connected to each other

- Game-style performance measures and high-scores list engages students in competing for better flood mitigation scenarios historical and actual events

- Rich visualizations and animations allow students to observe hydrological concepts and their effects in real-time

- Online training platform serves as a 24/7 hydrology lab for students to access from their home, and reduce the load or need for teaching assistants

The platform will be integrated to the engineering and science curriculum introducing hydrological processes and concepts in Civil and Environmental Engineering and Geography departments. The platform can be used to enhance the teaching effectiveness of any course with hydrological concepts. A large audience from various engineering and science courses can utilize the platform for their teaching and research purposes. The success of the project can be assessed through quizzes, and feedback from the students and teaching assistants (TAs). Training can be provided to TAs with an orientation. An additional outcome is the student's evaluations of the learning platform (e.g., what worked or not, what needs improvement, etc.). Surveys can also be conducted for measuring students' engagement and satisfaction with the platform.

\section{Conclusion}

The simulation systems provides a visually striking platform with realistic terrain information, and water simulation. Students can create and modify predefined scenarios, control environmental parameters, and evaluate flood mitigation techniques. The web-based simulation system provides an environment for students to learn about the flooding, flood damage, and effects of development and human activity in the floodplain. The system utilizes latest web technologies and graphics processing unit (GPU) for water simulation and object 
collisions in the floodplain. The system provides various scenarios customized to fit the age and education level of the users in three visualization and interaction mode using virtual, augmented and immersive reality modes. The system is still under development to introduce additional concepts in hydrology, new interaction modes, and integration of real-time data from Iowa.

\section{Bibliography}

1. Smits, P., Annoni, A., Craglia, M., 2009. One Information Space, Billions of Sensors, Technologies for Information Management, ICT FP7 Call 5 Intelligent Information Management, 11-12, May 2009.

2. Granell, C., Díaz, L., Schade, S., Ostländer, N., Huerta, J., 2013. Enhancing integrated environmental modelling by designing resource-oriented interfaces, Environ. Modell. Softw., 39, 229-246.

3. Nativi, S., Mazzetti, P., Geller, G.N., 2013. Environmental model access and interoperability: The GEO Model Web initiative, Environ. Modell. Softw., 39, 214-228.

4. Granell, C., Díaz, L., Gould, M., 2010. Service-oriented applications for environmental models: Reusable geospatial services, Environ. Modell. Softw., 25, 2, 182-198.

5. Demir, I., Dissertation, Integrated Web-based Data Management, Analysis and Visualization: Towards an Adaptive Watershed Information System, 2010, University of Georgia.

6. Tarboton, D. G., Horsburgh, J. S., Maidment, D. R., Whiteaker, T., Zaslavsky, I., Piasecki, M., Goodall, J., Valentine, D., Whitenack, T. 2009. Development of a community hydrologic information system. Modelling and Simulation Society of Australia and New Zealand and International Association for Mathematics and Computers in Simulation, pp. 988-994.

7. Williams, D.N., Ananthakrishnan, R., Bernholdt, D.E., Bharathi, S., Brown, D.I., Chen, M., Chervenak, A.L., Cinquini, L., Drach, R., Foster, I.T., Fox, P., Fraser, D., Garcia, J., Hankin, S., Jones, P., Middleton, D.E., Schwidder, J., Schweitzer, R., Schuler, R., Shoshani, A., Siebenlist, F., Sim, A., Strand, W.G., Su, M., Wilhelmi, N.C., 2009. The Earth System Grid: Enabling access to multimodel climate simulation data. Bulletin of the American Meteorological Society, 90, 195-205.

8. Demir, I., Beck, M.B., 2009. GWIS: A Prototype Information System for Georgia Watersheds, Paper 6.6.4, in Proceedings Georgia Water Resources Conference: Regional Water Management Opportunities, April 27-29, 2009, UGA, Athens, GA, US.

9. Demir, I., Jiang, F., Villarroel Walker, R., Parker, A.K., Beck, M.B., 2009. Information systems and social legitimacy: scientific visualization of water quality. In Proceedings of IEEE Int. Conference on Systems, Man, and Cybernetics, 1093-1098, October 11-14, 2009, San Antonio, TX, US.

10. Demir, I., Krajewski, W.F., Towards an integrated Flood Information System: Centralized data access, analysis, and visualization, Environmental Modelling \& Software, 50, pp. 77-84, 2013

11. Goodall, J.L., Horsburgh, J.S., Whiteaker, T.L., Maidment, D.R., Zaslavsky, I., 2008. A first approach to web services for the national water information system. Environ. Modell. Softw., 23, 4, 404-411.

12. Tuchyna, M., 2006. Establishment of spatial data infrastructure within the environmental sector in Slovak Republic. Environ. Modell. Softw., 21, 11, 1572-1578.

13. Bailenson, J. N., Yee, N., Blascovich, J., Beall, A. C., Lundblad, N., \& Jin,. (2008). The use of immersive virtual reality in the learning sciences: Digital transformations of teachers, students, and social context. The Journal of the Learning Sciences, 17, pp. 102-141.

14. Walser, R. (1992). Construction in cyberspace. Paper presented at the Education Foundation of the Data Processing Management Association Conference on Virtual Reality, Washington, DC. 